\title{
Vulnerability Assessment of Snowstorm in Altay
}

\author{
Guili Sun ${ }^{1,2}$ Zhen Cao $^{1}$ Lu Li $^{1}$ Haiyan Lu ${ }^{1}$
}

1. Forestry and Horticulture Department, Xinjiang Agriculture University 'Urumqi, Xinjiang, 830052, China;

2. Key Laboratory at Universities of Education Department of Xinjiang Uygur Autonomous Region, Urumqi, Xinjiang 830052, China

\begin{abstract}
This paper takes the county-level administration of Altay as the evaluation unit, and uses the frequency of historical snowstorm as the expression of the risk of snowstorm disaster in Altay area. The snow disaster vulnerability index system is established from snow physical exposure, sensitivity and disaster response capacity three aspects. The analysis is carried out by GIS software. The results show there is positive correlation between snow disaster risk and snowstorm vulnerability. And the snow disaster vulnerability is the highest in the Habahe County. The second is Jimunai County and Burqin County, Fuyun County and Qinghe County, while snow disaster vulnerability are lower in Altay City, Fuhai County. It is concluded that the defense of the snow disaster in Habahe County, Jimu Nai County, Fuyun County and Qinghe County should be regarded as the key areas of snow disaster prevention in the future.
\end{abstract}

Key words: Altay; Snowstorm; Vulnerability; GIS; Assessment

\section{阿勒泰地区雪灾易损性评估}

\author{
孙桂丽 ${ }^{1,2}$ 曹珍 ${ }^{1}$ 李路 ${ }^{1}$ 陆海燕 ${ }^{1}$ \\ 1 新疆农业大学林学与园艺学院, 乌鲁木齐 830052 , 中国 \\ 2 干旱区林业生态与产业技术重点实验室, 乌鲁木齐 830052, 中国
}

摘要：本文以阿勒泰地区县级行政单位为评估单元，以历史雪灾频率作为雪灾致灾危险性评 估指标。雪灾易损性评估采用雪灾物理暴露、敏感性和应灾能力 3 个方面指标，利用 GIS 空间分析功能分别对阿勒泰地区的雪灾危险性和易损性进行时段分析与综合分析，结果表 明：雪灾危险性与雪灾易损性呈正相关，且哈巴河县雪灾易损性最高，其次是吉木乃县和布 尔津县, 富蕴县和青河县易损性中等, 而阿勒泰市、福海县雪灾易损性都处于较低或低的水 平，因此今后阿勒泰地区雪灾防御的重点区域为哈巴河县、吉木乃县和布尔津县。

关键词：雪灾；易损性；GIS ; 评估；阿勒泰地区

\section{1. 引言}

雪灾亦称白灾，是因长时间大量 降雪造成大范围积雪成灾自然现象 ${ }^{[1]}$ 。 雪灾导致交通受阻、房屋倒塌、牲畜 冻死, 经济损失严重, 故引起众多学

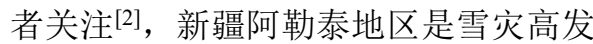
区，雪灾类型包括：雨雪灾、雪崩、 风吹雪, 暴风雪等。郭城等 ${ }^{[3]}$ 研究阿勒
泰地区大到暴雪的天气气候特征。李 博渊等 ${ }^{[4]}$ 运用信息扩散理论等方法研究 阿勒泰地区强降雪特征量的异常特征 及风险区划。田忠锋等 ${ }^{[5]}$ 通过阿勒泰地 区气象站统计历史降雪数据, 发现极 端雪灾的可能性北部、东部较大, 福 海站最小。刘兴元等[6]选择自然和社会 经济两大系统 20 项指标, 建立了灾情 判别模型和灾害损失估测模型, 定量 描述牧区雪灾状况。大多数学者的研 
究都只反应出阿勒泰地区雪灾的危害 程度和灾情状况, 对该地区的经济指 标所决定的易损性没有太多探讨，而 我国其它雪灾高发区在雪灾易损性评 估方面已有成果。如伏洋 [7]基于 GIS 综 合分析青海省雪灾的危险性以及社会 经济易损性。李丹 ${ }^{[8]}$ 从内蒙古牧区雪灾 致灾危险性和承险体易损性 2 个方 面, 选取三大类 9 项指标, 对内蒙古 牧区雪灾进行易损性评估。易损性 ${ }^{[9]}$ 是 区域社会经济系统对自然灾害的承受 能力和对灾害损失的敏感程度。本文 根据此定义, 在已有研究基础上, 结 合研究区情况选取合适指标, 利用 GIS 综合评估阿勒泰地区雪灾易损性, 为 该区防灾减灾提供科学依据。

\section{2. 资料来源与研究方法}

\section{1. 资料来源}

研究中经济指标数据来源于: 《新疆统计年鉴》（1996-2015 年）、 《中国县市社会经济统计年鉴》 （2001-2015 年）、《新疆五十年》。 研究中使用雪灾频率主要包括: 阿勒泰 地区 7 个国家级基准、基本气象站 1996-2014 年 1 月至次年 3 月 $24 \mathrm{~h}$ 降水 量 $>6 \mathrm{~mm}$ 的日数, 以及查阅阿勒泰地 区气象局、新疆自治区各类防灾减灾 部门的有关报道。

\section{2. 易损性评估指标及权重确定}

本文建立的阿勒泰地区雪灾易损 性评估的指标体系共包括 3 级, 为解 决指标的计量单位不统一, 取值范围 变幅大等问题，本文采用下面公式对 指标数据进行归一化处理 ${ }^{[10]}$ :

$$
Y_{i j}=\frac{x_{i j}-x_{i \min }}{x_{i \max }-x_{i \min }}
$$

指标权重的确定采用的是熵权 法, 熵权法的基本思路是根据指标变 异性的大小来确定权重 ${ }^{[11]}$ 。最后确定 易损性体系分层及权重见表 1 :
表 1 阿勒泰地区雪灾易损性指标及权重

\begin{tabular}{cll}
\hline 因子层 & 子因子层 & 指标层 \\
\hline 物理暴露 & 生命暴露性 & 人口密度 $(0.72)$ \\
$(0.65)$ & & 牲畜年底头数 $(0.28)$ \\
敏感性 & 生命敏感性 & 农业人口比例 $(0.74)$ \\
$(0.29)$ & & 小畜比例 $(0.26)$ \\
应灾能力 & 基础应灾能力 & 医疗卫生机构床位数 \\
$(0.06)$ & $(0.23)$ & $(0.34)$ \\
& & 城乡居民储蓄存款余额 \\
& & $(0.41)$ \\
& & 通讯能力 $(0.25)$ \\
& 专项应灾能力 & 灾害预报能力 \\
& $(0.67)$ & \\
& 救灾环境条件 & 公路网密度 \\
& $(0.10)$ & \\
\hline
\end{tabular}

本文将阿勒泰地区雪灾易损性评 估的模型定义为: $S=P+S+1 / E$ 。其中 $S$ 为易损性指数, $\mathrm{P}$ 为物理暴露指数, $\mathrm{Q}$ 为敏感性指数, $E$ 为应灾能力指数。

\subsection{GIS 空间分析}

本文采用的分析方法与梁凤娟等 [12-13]类似, 即建立雪灾数据库, 对数 据库数据进行叠加分析和计算, 对导 出新的数据进行空间插值, 插值方法 采用的是反距离权重法, 最后将插值 后的数据形成栅格图层, 通过计算、 掩膜提取, 得到每个栅格的分布指 数, 而分级方法采用自然断点法。

\section{3. 结果与分析}

\section{1. 雪灾致灾危险性评估}

对阿勒泰地区 1995-2014 年各县级 单元发生的雪灾进行统计, 分别计算 出 1995-2004 年、2005-2014 年各县域 单元的雪灾频率，最后综合计算二十 年的雪灾频率（图 1、2）。分析图 1、2 可知: 在 1995-2004 年间阿勒泰 市、布尔津县以及富蕴县雪灾频率最 高, 而福海县雪灾发生频率最低。而 在 2005-2014 年间, 雪灾频率发生了改 变, 雪灾发生频率最高的县市是阿勒 泰市、富蕴县、青河县, 频率最低仍 是福海县。 

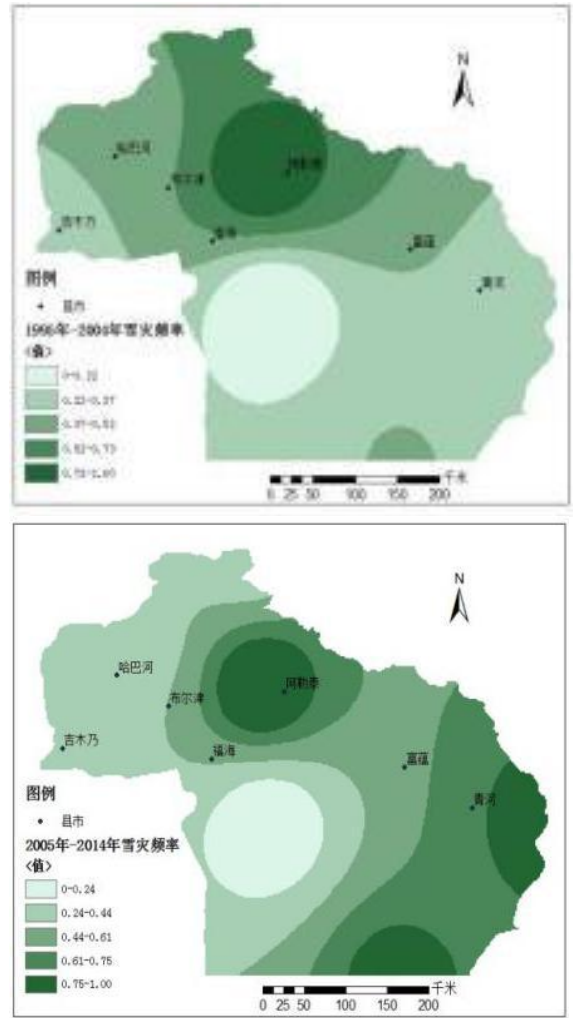

图 1 阿勒泰地区分段雪灾频率分布图

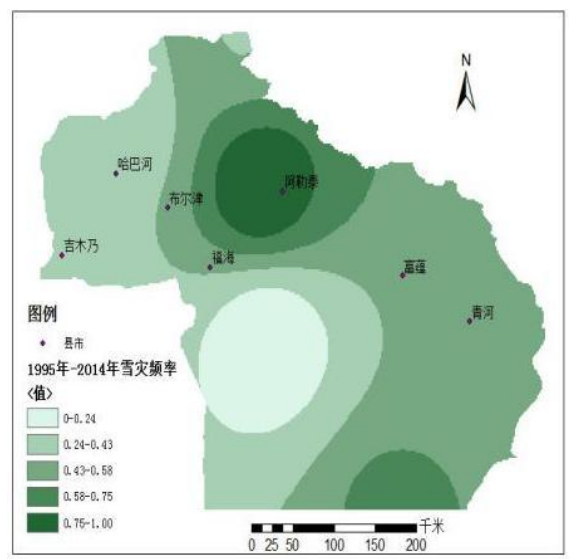

图 2 综合致灾危险性分布图

综合分析 1995-2014 年的历史雪灾 频率, 发现阿勒泰地区雪灾致灾危险 性为: 阿勒泰市、富蕴县、青河县最 大，布尔津县、哈巴河县、吉木乃县 次之, 福海县最小。这一结果与田忠
锋等 ${ }^{[4]}$ 的阿勒泰地区出现极端雪灾的可 能性北部（阿勒泰站）、东部（富 蕴、青河站) 较大, 福海站最小的结 论基本吻合。

\section{2. 雪灾承险体易损性评估}

\subsection{1 承险体物理暴露分析}

承险体物理暴露是暴露在雪灾影 响范围内的承险体 (如人口、牲畜、 房屋、农田等) 的数目或价值量, 是 雪灾风险存在的必要条件 [10]。对指标 进行归一化处理, 阿勒泰地区雪灾承 险体物理暴露综合计算公式为: $\mathrm{P}=0.72 \mathrm{P}_{1}+0.28 \mathrm{P}_{2}$, 其中 $\mathrm{P}$ 代表总物 理暴露度, $\mathrm{P}_{1} \mathrm{P}_{2}$ 分别代表人口密度和牲 畜年底头数, 常数为熵权法得到的权 重, 通过上式综合计算, 最后在 GIS 中进行分级, 得到阿勒泰地区雪灾承 险体综合物理暴露度（图 3）。

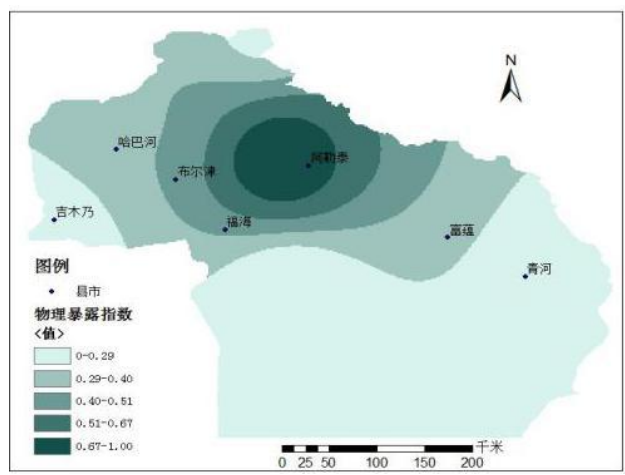

图 3 雪灾承险体综合物理暴露分布图

从图 3 可得：阿勒泰地区物理暴 露指数阿勒泰市、哈巴河县最大，布 尔津县、富蕴县次之, 青河县、福海 县、吉木乃县较小。阿勒泰市和布尔 津县人口分布密集, 其物理暴露程度 明显高于其它地区。而富蕴县虽然人 口密度较小, 但牲畜年底头数较大导 致其物理暴露程度也较高。

\subsection{2 承险体敏感性分析}

承险体敏感性指由承险体本身的 物理特性决定的受一定打击后受到损 失的容易程度, 它反映了承险体本身 
抵御雪灾打击的能力 ${ }^{[10]}$ 。阿勒泰地区 雪灾承险体的敏感性的计算公式为:

$Q=0.76 Q_{1}+0.24 Q_{2}$, 其中 $Q$ 代表总 敏感性, $Q_{1} 、 Q_{2}$ 分别代表农业人口比 例和小畜比例, 常数为熵权法得到的 权重, 通过上式综合计算, 最后在 GIS 中进行分级, 得到阿勒泰地区雪灾承 险体综合敏感性（图 4）。

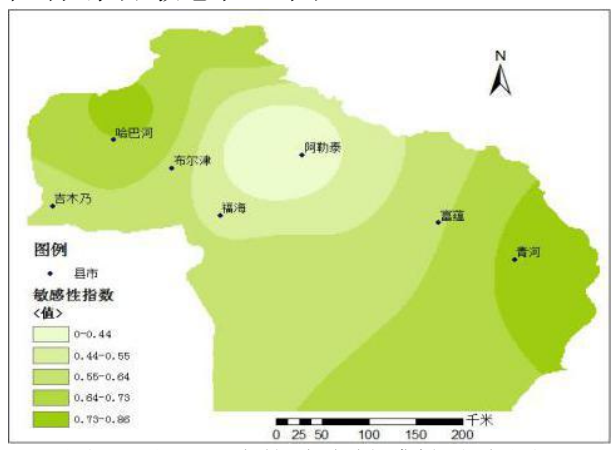

图 4 雪灾承险体综合敏感性分布图

图 4 表明阿勒泰地区雪灾承险体 敏感性最高的是哈巴河县和青河县, 布尔津县和富蕴县次之, 福海县和吉 木乃县敏感性较低, 阿勒泰市最低。 分析可知农业人口比例大的地区, 如 哈巴河县和青河县, 其敏感程度明显 较高, 而小畜比例较大的富蕴县和吉 木乃县, 其敏感性程度也相对较高。

\subsection{3 应灾能力分析}

某地区的雪灾应灾能力反应的是 人类社会为免受、少受雪灾威胁所拥 有的基础条件及专项的防御雪灾措 施。承险体的应灾能力是雪灾能否发 生以及发生程度大小的重要影响因素 [10]。本文分析阿勒泰地区雪灾应灾能 力包括基础应灾能力、专项应灾能力 和救灾环境条件三个方面。

（1）基础应灾能力。雪灾基础应 灾能力的综合计算公式为: $\mathrm{D}=0.34 \mathrm{D}_{1}+0.41 \mathrm{D}_{2}+0.25 \mathrm{D}_{\mathrm{a}}$, 其中 $\mathrm{E}$ 代表总基础应灾能力, $\mathrm{D}_{1} 、 \mathrm{D}_{2} 、 \mathrm{D}_{2}$ 分别代表医疗卫生机构床位数、城乡 居民储蓄存款余额和通讯能力, 常数
为熵权法得到的权重，通过综合计算 分级, 得到阿勒泰地区雪灾基础应灾 能力（图 5)。

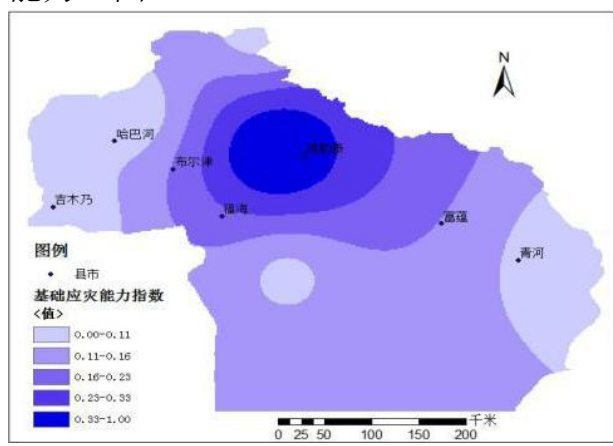

图 5 雪灾基础应灾能力分布图

从图 5 来看, 阿勒泰地区雪灾基 础应灾能力最强的是阿勒泰市, 福海 县、富蕴县、布尔津县次之, 最弱的 地区是哈巴河县、吉木乃县以及青河 县。分析发现医疗卫生机构床位数、 城乡居民储蓄存款余额、县市本地电 话年末用户数量普遍都高的县市基础 应灾能力高。

（2）专项应灾能力。专项应灾能 力, 葛全胜等 ${ }^{[11]}$ 认为是为特定自然灾 害防治所提供的各种工程和非工程的 抗灾措施力度, 本文主要探讨灾害预 报能力, 选取阿勒泰地区所有气象站 点数量, 并在 GIS 中对其进行密度分 析, 来表达阿勒泰地区雪灾的专项应 灾能力, 结果见图 6 。

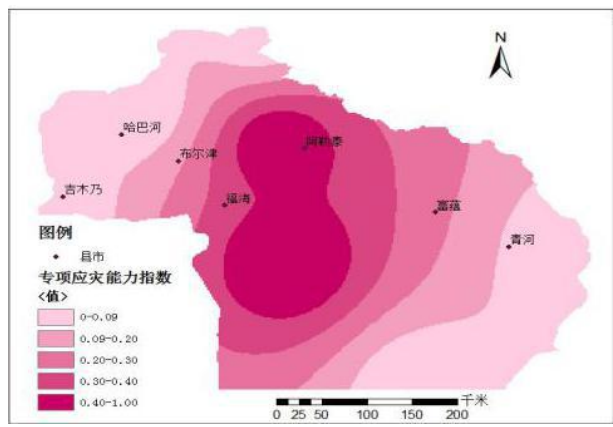

图 6 雪灾专项应灾能力分布图

（3）救灾环境条件。阿勒泰地区 人口密度低, 地形复杂, 如果雪灾发 
生, 交通状况是否良好是影响雪灾救 援的一项重大因素。基于数据可操作 性, 选区公路网密度作为阿勒泰地区 雪灾救灾环境条件的评估指标, 在 GIS 的空间分析中得到阿勒泰地区救灾环 境条件分布图（图 7)。

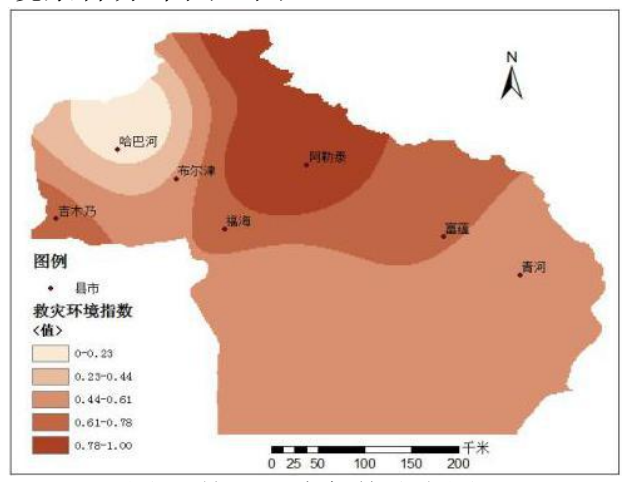

图 7 救灾环境条件分布图

从图 7 可知, 阿勒泰市、布尔津 县、吉木乃县救灾环境条件较好, 福 海县、青河县、富蕴县次之, 救灾环 境条件最差的是哈巴河县。

（4）应灾能力综合分析。分析基 础应灾能力、专项应灾能力和救灾环 境条件, 得出综合应灾能力为: $\mathrm{E}=0.23 \mathrm{E}_{1}+0.67 \mathrm{E}_{2}+0.10 \mathrm{E}_{\mathrm{a}}$, 其中 $\mathrm{E}$ 代表总应灾能力, $\mathrm{E}_{1} \mathrm{E}_{2} \mathrm{E}_{\mathrm{a}}$ 分别代表基 础应灾能力、专项应灾能力和救灾环 境条件, 常数为摘权法得到的权重, 综合计算分级, 得到阿勒泰地区雪灾 综合应灾能力（图 8)。

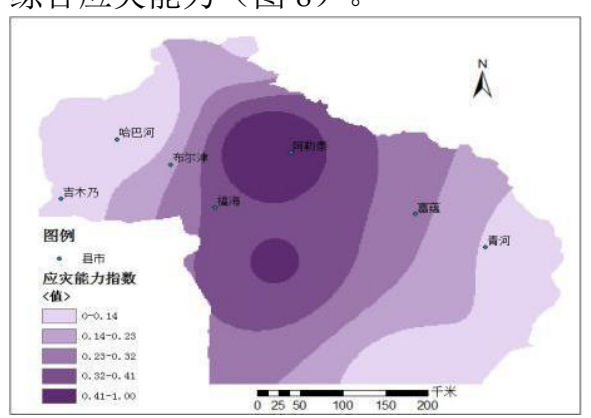

图 8 雪灾综合应灾能力分布图

从图 8 对阿勒泰地区雪灾的综合 应灾能力分析发现其与专项应灾能力
的强弱较为相似, 都是阿勒泰市和福 海县较强, 布尔津县和富蕴县次之, 而哈巴河县、吉木乃县、青河县较 弱。气象站分布密集的县市整体应灾 能力也较高, 而道路不便、储蓄较 低、通讯不发达等基础条件较差的地 区应灾能力普遍较弱。

\subsection{4 综合易损性分析}

根据上面对雪灾承险体物理暴 露、敏感性以及应灾能力分析, 其雪 灾综合易损性计算公式为: $S=0.65 P+0.29 Q+0.06 \frac{1}{E}$, 其中 $S$ 为 雪灾易损性指数, $\mathrm{P}$ 为物理暴露指数, $\mathrm{Q}$ 为敏感性指数, $\mathrm{E}$ 为应灾能力指数。 通过计算分析得到阿勒泰地区雪灾的 综合易损性（图 10），同时进行雪灾 承灾体易损性分段分析（图 9）。

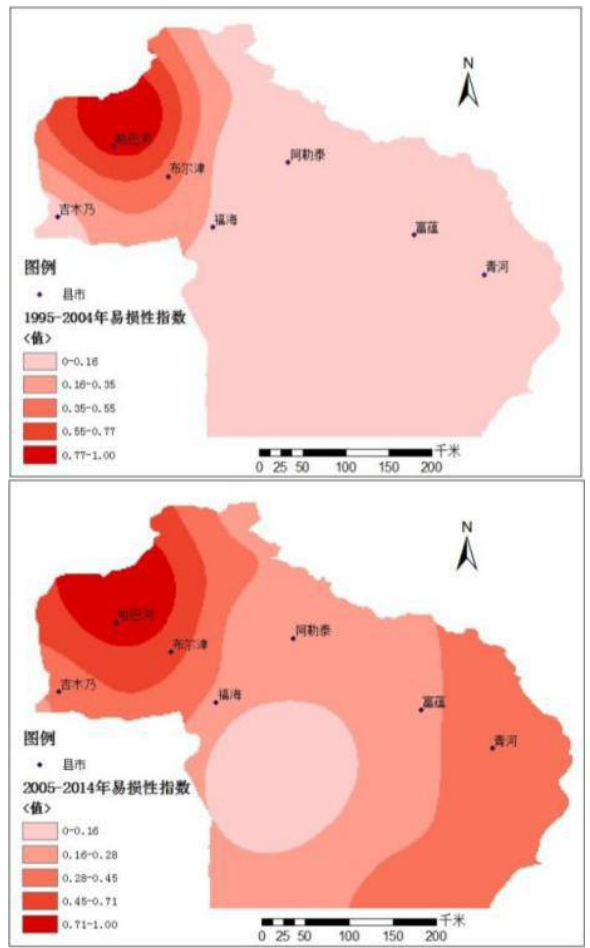

图 9 阿勒泰地区分段雪灾易损性分布图

分析图 9 发现, 部分县市的雪灾 易损性 2005-2014 年较 1995-2004 年有 
所增加, 但整体可以看出, 雪灾易损 性较大与较小地区没有太多改变, 说 明综合雪灾易损性数据较为客观反映 了雪灾易损性大小。

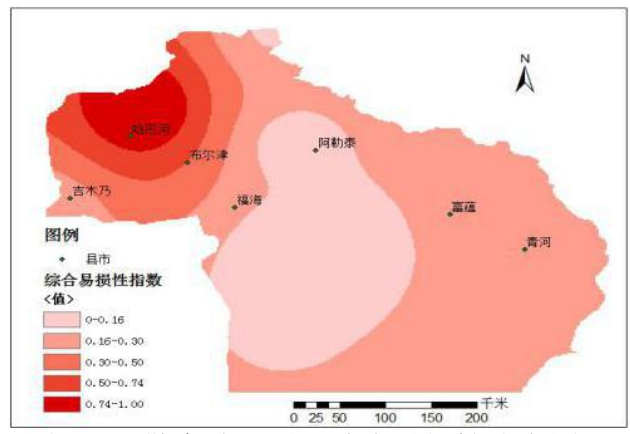

图 10 阿勒泰地区雪灾综合易损性分布图

同时结合之前 3.1 做的分段雪灾频 率分布图分析可知, 大部分县市 20052014 年间雪灾频率增加, 且此时间雪 灾易损性指数也有所增加, 故即雪灾 危险性越大，雪灾易损性也越大。

从图 10 结果来看, 阿勒泰地区雪 灾承灾体易损性哈巴河县最高, 其次 是吉木乃县和布尔津县, 富蕴县和青 河县易损性中等, 而阿勒泰市、福海 县易损性处于较低或低水平。

\section{4. 结论与讨论}

对比危险性和易损性指数发现， 哈巴河县、吉木乃县、富蕴县、青河 县四个县不论是危险性还是易损性都 较高, 而哈巴河县明显高于其它县 市。哈巴河县、吉木乃县、富蕴县、 青河县为雪灾高易损性地区, 尤其是 哈巴河县雪灾防御应该作为阿勒泰地 区今后雪灾防御的重点区域。通过加 大高易损区的通讯能力、重点保护当 地小畜、强化灾害预报效率等手段进 行灾前减灾和防灾工作。

\section{致谢}

基金项目: 国家自然科学基金 (41361093)

\section{参考文献}

[1]李培基,米得生.中国积雪分布 $[\mathrm{J}]$. 冰 川冻土, 1983,5(4):9-17.

[2]唐良东.雪灾对宣城地区林分的影响 及生态恢复措施 [J]. 现代农业科技, 2010, 09:312-317.

[3]郭城,李博渊,杨森,庄晓翠,王海岩.新 疆阿勒泰地区大到暴雪天气气候特征 [J].干旱气象, 2012,30(4):604-608.

[4]李博渊,王小号. 阿勒泰地区强降雪灾 害风险研究 [J]. 沙漠与绿洲气象, 2016,10(3):47-52.

[5]田忠锋, 胡䂞, 李博渊.新疆阿勒泰地 区大到暴雪概率分布特征 $[\mathrm{J}]$. 陕西气象, 2016,03:12-16.

[6]刘兴元,陈全功,梁天刚, 郭正刚,柴琦. 新疆阿勒泰牧区雪灾遥感监测体系构 建与灾害评价体系研究 [J]. 应用生态学 报, 2006, 17(2):215-220.

[7]伏洋, 肖建设,校瑞香,酒文君, 李凤霞. 基于 GIS 的青海省雪灾风险评估模型 [J].农业工程学报,2010,S1:197-205.

[8]李丹.1981-2013 年内蒙古牧区雪灾 风险评估 [J].内蒙古气象,2015,06:19-23. [9]何爱平.中国灾害经济: 理论构架与 实证研究[D].西北大学博士论文,2002. [10]刘栎杉,延军平. 阿勒泰地区冬季降 水变化特征及雪灾趋势判断 $[\mathrm{J}]$. 干旱区 资源与环境,2013,09:72-78.

[11]刘佩.青藏高原雪灾风险评估[D].青 海师范大学,2012.

[12]周秉荣, 李凤霞, 申双和, 宋理明,李红 梅. 青海高原雪灾预警模型与 GIS 空间 分析技术应用 $[\mathrm{J}]$. 应用气象学 报,2007,03:373-379.

[13]梁凤娟,孟雪峰,王永清, 孙令东, 吕娜, 吴国周.基于 GIS 的雪灾风险区划 $[\mathrm{J}]$.气 象科技,2014,02:336-340.

[14]葛全胜,邹铭,郑景云.中国自然灾害 风险综合评估初步研究 [M]. 北京:科学 出版社.2008,2-275. 